\title{
Attenuation of the CS-preexposure effect after a retention interval in preweanling rats
}

\author{
PHILIPP J. KRAEMER, HEATHER HOFFMANN, and NORMAN E. SPEAR \\ State University of New York at Binghamton, Binghamton, New York
}

\begin{abstract}
The effects of flavor preexposure and retention interval were assessed in 6-and 12-day-old rats. Conditioned aversions to a flavor appeared at both ages. The conditioning of the younger pups was unaffected by conditioned stimulus (CS) preexposure and was not evident after a 10-day retention interval. For the 12-day-old rats, preexposure to either the flavor CS or a different flavor attenuated aversion strength when the rats were tested soon after conditioning. Other 12-dayold rats that were tested 10 days after conditioning also expressed substantial aversions, but with a retention interval of this length, the aversions were equivalent for animals preexposed to the CS and those not preexposed before conditioning. This loss of the CS-preexposure effect over a long interval, which has also been observed in adult rats, identifies the locus of this effect as postacquisition and perhaps at the stage of memory retrieval.
\end{abstract}

One approach to the ontogeny of learning and memory is to determine whether phenomena established for adults occur with the same characteristics when tested with younger animals. This strategy can provide insights relevant not only to our general understanding of information processing in animals, but also to that of the ontogeny of memory, particularly when there is reason to expect an age-related difference. The present experiment was initiated with this perspective in mind. We set out to determine whether certain characteristics of a conditioned tasteaversion phenomenon recently found in adult rats would differ for immature rats.

Adult rats often express weaker conditioned aversions to familiar tastes than to novel tastes (Best, 1975; Elkins, 1973; Garcia \& Koelling, 1967; Kalat \& Rozin, 1973; Nachman, 1970; Revusky \& Bedarf, 1967; Vogel \& Clody, 1972). This occurrence of latent inhibition (Lubow, 1973) has also been found with generalized taste aversions. Exposure to one taste can attenuate the strength of a conditioned aversion to another taste (Dawley, 1979; Tarpy \& McIntosh, 1977). More recent research has also shown that the taste-preexposure effect is influenced by retention interval. Specifically, Kraemer and Roberts (1984) found that preexposure to a taste attenuated taste aversions in adult rats tested soon after conditioning but had no effect following a relatively long retention interval.

This effect seems contrary to traditional interpretations of the preexposure effect. It has typically been assumed that prior experience with a taste impairs acquisition of

This research was supported by grants from the National Institute of Mental Health (1 R01 MH35219 to Norman E. Spear, 1 F32 MH09226 to Philipp Kraemer, and 1 F31 MH09469 to Heather Hoffmann). The authors express their appreciation to Norman G. Richter and Teri Tanenhaus for their assistance with the present research and report. Requests for reprints should be addressed to Norman E. Spear, Center for Developmental Psychobiology, Department of Psychology, University Center at Binghamton-SUNY, Binghamton, NY 13901. an aversion (Best \& Gemberling, 1977; Kalat \& Rozin, 1973; Lubow, 1973). The finding that preexposure effects dissipate over a long retention interval is inconsistent with this assumption. That a strong taste aversion was expressed after an extended retention interval suggests that the aversion had, indeed, been acquired. Perhaps prior taste experiences influence expression, rather than storage, of an acquired taste aversion.

One possible mechanism for such an effect could involve retrieval processes. The rat's memory of the preexposure might disrupt retrieval of the memory for the conditioning episode, perhaps due to associative interference. Assuming that forgetting of a preexposure experience over an extended retention interval exceeds that of the conditioning itself, retrieval interference from the preexposure also should decrease over such an interval. This would allow the animal to retrieve more selectively the memory for conditioning, and it would therefore be expected that strong aversions would be expressed after a long retention interval in spite of weak aversions shortly after conditioning.

In this study, we examined whether length of a retention interval would influence the taste-preexposure effect in 6- and 12-day-old rat pups. At one level, this study allowed us to assess the generality of the phenomenon found by Kraemer and Roberts (1984) with adults by testing the effect in much younger animals. This study also held the promise of interesting theoretical implications. If some type of memory processing mechanism did indeed underlie the taste-preexposure effect, then this effect in younger rats might vary in accord with age-specific features of other aspects of memory processing.

Prior research has indicated that conditioned taste aversions can be established in rat pups during their first 2 postnatal weeks (Gemberling \& Domjan, 1982; Gemberling, Domjan, \& Amsel, 1980; Hoffmann, Molina, Kucharski, \& Spear, 1987). It has also been shown that 
prior experience with either tastes or odors increases pups' preferences for these stimuli, and that such preferences are retained for at least $24 \mathrm{~h}$ (Caza \& Spear, 1984; Rudy, Vogt, \& Hyson, 1984). No evidence is available concerning the effect of taste preexposure on taste-aversion conditioning in rats as young as those tested in the present experiments ( 6 and 12 days postnatal). Perhaps it is relevant, however, that prior experience with an odor reduces the strength of a subsequent toxin-induced odor aversion in rat pups as young as 2 days of age (Rudy \& Cheatle, 1979).

The present study assessed the strength of a conditioned taste aversion as a function of preexposure and retention interval in 6- and 12-day-old rat pups. Preexposed animals of both ages experienced either the taste CS (primary exposure) or a taste different from the taste CS (generalized exposure) prior to a taste + lithium chloride ( $\mathrm{LiCl}$ ) conditioning episode. Nonpreexposed animals were conditioned without a prior taste experience, and control animals received no preexposure and a long-delay pairing of the taste CS with $\mathrm{LiCl}$. In separate animals, aversions were then tested in each of the four conditions after intervals of $20 \mathrm{~h}$ or 10 days.

Infants differ from adults in three respects that could alter the influence of a retention interval on the effect of CS preexposure. In comparison with adults, infants forget more rapidly, are more susceptible to a source of proactive interference, such as CS preexposure, and may have greater stimulus generalization (Campbell \& Haroutunian, 1979; Campbell \& Spear, 1972; Smith \& Spear, 1981). Their greater forgetting and greater susceptibility to interference should promote the same dependence of the CS preexposure effect on retention interval as has been observed in adults, if our interpretation of the effect is correct. Predictions regarding stimulus generalization are less clear. It has been found in adults that the attenuation effect dissipates more rapidly with generalized preexposure than with primary preexposure (Kraemer \& Ossenkopp, 1985; Kraemer \& Roberts, 1984). But if the infants exhibit greater stimulus generalization than adults, the effects of generalized and primary preexposure may be more similar for the younger animals than for the adults. Nevertheless, given that the effects of neither generalized nor primary taste preexposure had been assessed in younger rats, we were interested in determining whether an attenuation effect would appear even shortly after conditioning.

\section{METHOD}

\section{Subjects}

The subjects were 88 6-day-old rats derived from 10 litters and 75 12-day-old rats derived from 8 litters. All pups were housed with both parents and littermates in standard opaque maternity cages that were partially filled with pine shavings. Litters were culled to 10 pups $24 \mathrm{~h}$ following birth, with the date of parturition designated as Day 0. All animals were maintained on a 16:8-h light:dark illumination cycle. The lights came on at $6 \mathrm{a} . \mathrm{m}$.

\section{Apparatus}

Preexposure and conditioning were conducted in $17 \times 9 \times 19 \mathrm{~cm}$ Plexiglas chambers that were maintained at $32^{\circ}-34^{\circ} \mathrm{C}$ by heating pads placed beneath them. Ingestion tests after the 20 -h retention interval for rats of both ages and after the 10-day retention interval for the younger subjects were also performed in these chambers. Fluid infusions were delivered by a Sage Instruments syringe pump (Model 341A), and subjects were weighed using a Fisher/Ainsworth balance (Model MX-200) accurate to $0.01 \mathrm{~g}$. The consumption test for the 12-day-old subjects tested after the 10-day retention interval was conducted in individual standard wire-mesh cages. Pyrex (No. 3075$)$ drinking tubes $(10 \pm 0.1 \mathrm{ml})$ equipped with stainless steel spouts and rubber stoppers were attached to the front of these cages.

\section{Procedure}

The subjects in each age group were randomly divided into eight groups. Four groups were tested $20 \mathrm{~h}$ after conditioning; the other four similarly treated groups were tested after a 10-day retention interval. Conditioning consisted of an oral infusion of a $50 \%(\mathrm{v} / \mathrm{v})$ Dairylea chocolate-milk solution diluted with water, followed by an intraperitoneal injection of $0.3 \mathrm{M} \mathrm{LiCl}$. Group $\mathrm{CM}+$ received only this conditioning treatment. Before the rats in the other two conditioned groups were given conditioning (the pairing of chocolate milk and $\mathrm{LiCl}$ ), they received nonreinforced exposure to either the chocolate-milk solution (Group $\mathrm{CM}-/ \mathrm{CM}+$ ) or a $0.15 \%$ saccharin solution (Group S-/CM+). The pups in the conditioningcontrol group (Group UP, unpaired) were given the chocolate milk $\mathrm{CS}$ and the $\mathrm{LiCl}$ unconditioned stimulus (US) in an unpaired fashion, with a 3-h interval between infusion of the CS (chocolate milk) and administration of $\mathrm{LiCl}$.

Five hours prior to experimentation, the subjects were removed from the home cage and placed, with their littermates, into maternity cages partially filled with clean pine shavings. These cages were maintained at $32^{\circ}-34^{\circ} \mathrm{C}$ by heating pads placed beneath them. Pups of these ages do not readily consume fluids from drinking tubes, so it was necessary to implant a small piece of fine polyethylene tubing (Clay Adams, PE-10, $0.28 \mathrm{~mm}$ i.d.) in each animal's mouth for fluid delivery. This cannulation procedure was similar to that described by Hall and Rosenblatt (1977), except that the tubing was placed through the pup's cheek. Cannulation took approximately 5 sec per animal, and the pups appeared to suffer little trauma. The cannulated animals were then returned to the holding cages, where they remained deprived for $5 \mathrm{~h}$ prior to preexposure and/or conditioning.

For preexposure, Groups $\mathrm{CM}-/ \mathrm{CM}+$ and $\mathrm{S}-/ \mathrm{CM}+$ were given a 3-min infusion of either the chocolate milk or a $0.15 \%$ saccharin solution, respectively. The infusion rate for each animal corresponded to the delivery of approximately $1.8 \%$ of the subject's body weight over a 3-min period, and the rats could either consume or reject the infused solution.

One hour after preexposure, the subjects in Groups $\mathrm{CM}-/ \mathrm{CM}+$, $\mathrm{S}-/ \mathrm{CM}+$, and $\mathrm{CM}+$ were given a $5-\mathrm{min}$ infusion of chocolate milk at a rate similar to that used for preexposure. Thus the animals received an amount of fluid representing approximately $3 \%$ of their body weights over the 5 -min period. Immediately following CS presentation, the pups were injected with $0.3 \mathrm{M} \mathrm{LiCl}$ at $1 \%$ of their body weights. The rats in the UP groups were given a similar infusion of the CS, followed $3 \mathrm{~h}$ later by a $\mathrm{LiCl}$ injection.

The pups that were to be tested $20 \mathrm{~h}$ after conditioning were returned to the holding cages and remained deprived of maternal care and nourishment until tested. The pups that were to be tested at the 10-day retention interval had their cannulae removed and were returned to the home cage $1 \mathrm{~h}$ after conditioning. For the 20-h test, the pups had their bladders voided and then were weighed. These pups received a 5-min infusion of chocolate milk similar to that given during training. Afterwards, the rats were dried with absor- 
bent towels and again weighed. Their weights were assessed to the nearest $0.01 \mathrm{~g}$. The amount ingested was expressed in terms of percent body-weight gain [100 $\times$ (postinfusion weight - preinfusion weight)/preinfusion weight].

Six-day-old pups tested 10 days after conditioning were removed from the home cage at 15 days of age. These subjects were cannulated and then deprived for $20 \mathrm{~h}$ prior to testing, which was conducted as described above.

Twelve-day-old rats tested 10 days after conditioning were weaned from the home cage at $\mathbf{2 0}$ days of age. These subjects were then deprived of fluids for $\mathbf{4 8} \mathrm{h}$ prior to receiving a one-bottle consumption test. The amount (in milliliters) of chocolate milk consumed in $30 \mathrm{~min}$ was the dependent measure for these animals.

\section{RESULTS}

\section{Six-Day-Old Subjects}

The mean percent body-weight-gain scores for 6-dayold pups tested $20 \mathrm{~h}$ after conditioning are shown in Figure 1. A one-way analysis of variance (ANOVA) performed on the data revealed a significant main effect of treatment $[F(3,44)=2.907, p<.04]$. Individual group mean comparisons were performed using a Fisher test ( $p=.05 ;$ Keppel, 1982). These comparisons revealed that, independent of preexposure treatment, subjects that had been given chocolate milk paired with $\mathrm{LiCl}$ consumed significantly less of the milk solution than did control (UP) animals. The three conditioned groups $(\mathrm{CM}+$, $\mathrm{S}-/ \mathrm{CM}+$, amd $\mathrm{CM}-/ \mathrm{CM}+$ ) did not differ. These results confirm that taste aversions were established in the 6-day-old subjects, but neither preexposure to the CS itself (chocolate milk) nor preexposure to another taste (saccharin) reduced the strength of the aversion.

Data for the 6-day-old subjects tested after a 10-day retention interval are presented in Figure 2. A one-way ANOVA indicated that no significant differences existed among the treatment groups.

A two-way factorial ANOVA (treatment $x$ retention interval) revealed that overall consumption was greater after the 10-day retention interval than after the 20-h interval $[F(1,80)=4.1, p<.001]$, and that the treatment $\times$ retention interval interaction did not reach significance $[F(3,80)=.13]$. This analysis indicated that consumption generally increased over the 10 -day retention interval. On the basis of separate relative comparisons between

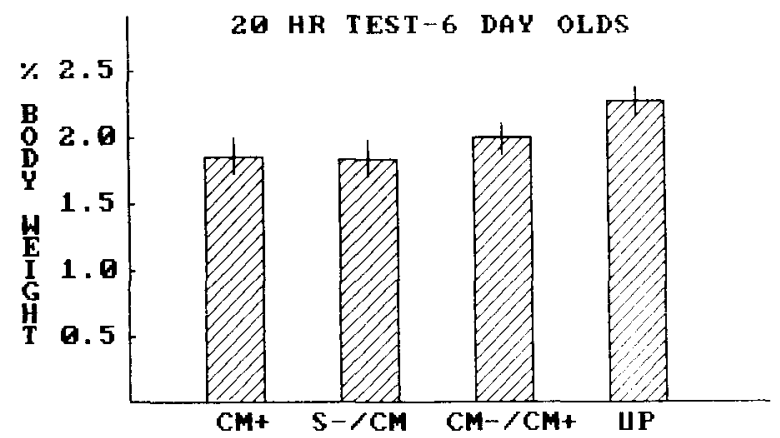

Figure 1. Mean $( \pm S E)$ percent body-weight gain for 6-day-old pups from the four treatment groups tested at the 20-h retention interval.

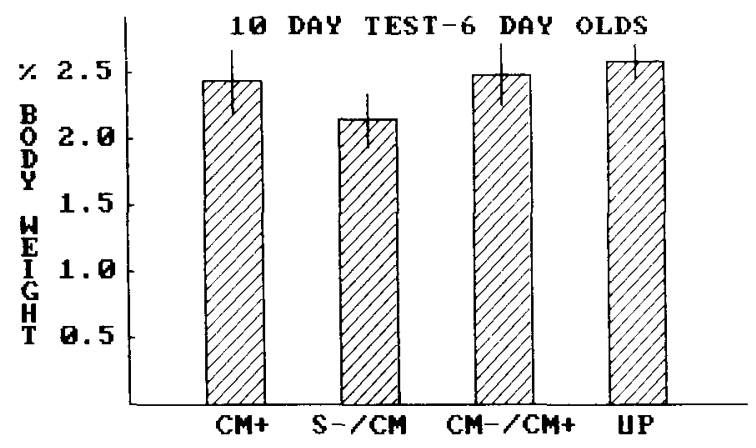

Figure 2. Mean $( \pm S E)$ percent body-weight gain for 6-day-old pups from the four treatment groups tested at the 10-day retention interval.

treatment conditions at each retention interval, there is a suggestion that aversions were forgotten over the 10day interval. The three conditioned groups consumed less than the unpaired control group after the 20-h test, but consumption among the conditioned groups did not differ from that of the unpaired control group after the 10-day retention interval. Despite the lack of an interaction between treatment and retention interval, it is difficult to conclude that retention was sufficient after the longer retention interval to permit a clear conclusion about latent inhibition at that point. In view of the known susceptibility of infant rats to forgetting, these data probably indicate forgetting over this 10 -day period.

\section{Twelve-Day-Old Subjects}

The mean percent body-weight-gain scores for the older rats tested after the short retention interval are presented in Figure 3. There were significant differences between conditioned and control groups and also between preexposed and nonpreexposed subjects. An ANOVA performed on the data revealed a significant main effect of treatment $[F(3,28)=4.42, p<.01]$. Post hoc comparisons showed that rats in the conditioned groups $(\mathrm{CM}+$, $\mathrm{CM}-/ \mathrm{CM}+$, and $\mathbf{S}-/ \mathbf{C M}+$ ) ingested significantly less chocolate milk than did the UP control animals. Rats that were preexposed to either the CS or to a saccharin solution, however, consumed significantly more of the CS solution than did nonpreexposed subjects. These two preexposed groups did not differ.

Twelve-day-old rats, like the 6-day-old rats, acquired an aversion to the chocolate-milk solution. But, unlike the younger pups, exposure to the CS or to a different taste prior to conditioning attenuated this aversion in the older pups. The degree of attenuation did not differ for primary and generalized preexposure.

The amount (in milliliters) of chocolate-milk solution consumed by 12-day-old subjects tested 10 days after conditioning is shown in Figure 4. Evidence of a conditioned aversion was apparent for the older pups tested after this longer interval. More importantly, however, the preexposed animals tested at this later time had taste aversions similar to those seen in the nonpreexposed rats. An 


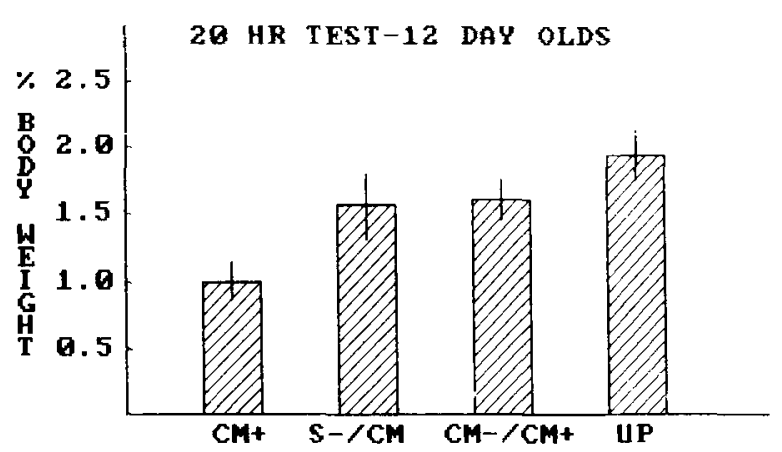

Figure 3. Mean ( $\pm S E$ ) percent body-weight gain for 12-day-old pups from the four treatment groups tested at the 20-h retention interval.

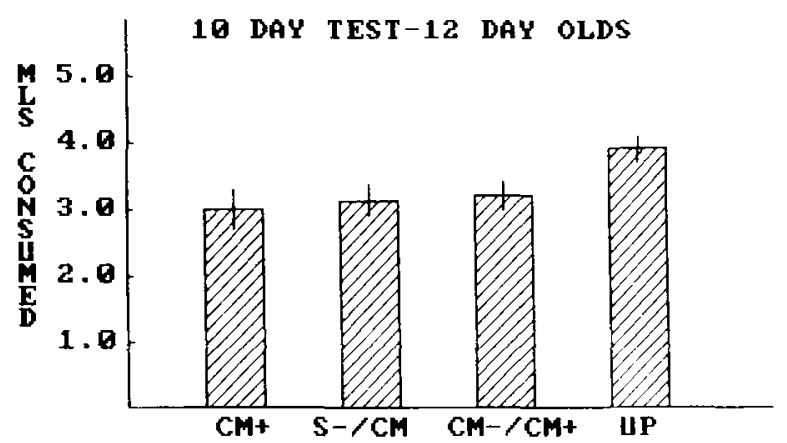

Figure 4. Mean $( \pm S E$ ) milliliters of chocolate milk consumed by the 12-day-old pups from the four treatment groups tested at the 10-day retention interval.

ANOVA on these data indicated a significant main effect of treatment $[F(3,37)=2.859, p<.04]$. Fisher tests revealed that all subjects that had been given a pairing of chocolate milk and $\mathrm{LiCl}$ drank significantly less of that solution than did control animals, but there were no differences among the conditioned groups $(\mathrm{CM}+, \mathrm{S}-/ \mathrm{CM}+$, and $\mathrm{CM}-/ \mathrm{CM}+$ ).

The attenuation of conditioned aversion due to CS preexposure was not evident after the 10-day interval.

\section{DISCUSSION}

The results indicated that both 6- and 12-day-old rats acquired a conditioned aversion to chocolate milk and retained the aversion for at least $20 \mathrm{~h}$. This finding provides new information concerning the viability of conditioning in preweanling rats. Rats that were 1 or 5 days postnatal had seemed to acquire readily a conditioned taste aversion with saccharin as the $\mathrm{CS}$ and $\mathrm{LiCl}$ as the US (Gemberling \& Domjan, 1982; Gemberling et al., 1980); 5and 9-day-old rats had seemed similarly adept at such conditioning with a sucrose $\mathrm{CS}$ and a $\mathrm{LiCl}$ US (Hoffmann et al., 1987). However, two other studies with slightly different procedures have led to the conclusion that, at least with sucrose as the $\mathrm{CS}$ and $\mathrm{LiCl}$ as the US, conditioned taste aversion may not occur reliably before about
12 days postnatal due to neuroanatomical immaturity (Vogt \& Rudy, 1984a, 1984b). The present experiment adds generality to the previous positive results by adding chocolate milk to the list of substances to which a conditioned aversion is acquired by rats during their first postnatal week. It is perhaps notable that, of the three sets of experiments reporting positive results in the conditioning of taste aversion during the first postnatal week, the present one employed the longest conditioning-to-test interval $(20 \mathrm{~h})$. A rough estimate of relative conditioning strength based on absolute differences between conditioned and unpaired animals suggests that the present conditioned aversion also was the weakest of the three. Yet the present conditioning-to-test interval of $20 \mathrm{~h}$ is still short relative to the 48-h interval in the studies that did not detect conditioning (although Vogt \& Rudy, 1984a, also failed to find conditioning with a $12-\mathrm{h}$ interval). The long conditioning-to-test interval in those tests may have been one of the procedural circumstances that precluded conditioning (for another, see Hoffmann et al., 1987).

Although evidence of learned aversions appeared in both 6- and 12-day-old rats, taste preexposure impaired conditioning in only the older pups. Prior experience with either the taste that later served as the CS (chocolate milk) or a taste different from the CS (saccharin) reduced the magnitude of an acquired aversion to chocolate milk in 12-day-old rats tested at the 20-h interval, but not in 6day-old rats. This occurred despite the fact that conditioning without preexposure was at least as strong in the older pups, and probably stronger.

Several possible explanations can be offered for this apparently ontogenetic difference in susceptibility to latent inhibition. First, perhaps processes responsible for the appearance of latent inhibition itself are not functional in the 6-day-old rat. Such a possibility would be consistent with some data (Hoffman, 1985) and with the general idea that the ontogenesis of learning may involve the gradual development of specific components of the learning process (Rudy et al., 1984). Evidence against such an account, however, has already been provided by Rudy and Cheatle (1979), who found that preexposure to the CS attenuated odor aversions in 7-day-old rat pups. This finding contradicts the notion that latent inhibition itself does not appear in very young rats, although it remains possible that the expression of latent inhibition depends on the sensory modality involved in the conditioning. Although very young rats may be capable of exhibiting latent inhibition, such an ability may be expressed at different ages with different sensory systems.

A second possible reason for the age-related differences in latent inhibition involves forgetting. In adult rats, the expression of attenuated aversions that often results from CS preexposure has been found to decrease when a delay interval is interpolated between either preexposure and conditioning or conditioning and testing, with the implication that latent inhibition may involve retrieval mechanisms rather than storage operations (Kraemer \& Roberts, 1984). Perhaps the 6-day-old rats failed to manifest a 
preexposure effect because the 20 -h retention interval was sufficient at this age to induce the effect observed after longer intervals by Kraemer and Roberts for adults and in the present study for 12 -day-old rats. With the 20 -h retention interval, the 12-day-old animals in the present study exhibited weakened aversions to chocolate milk following preexposure to either chocolate milk or saccharin. But when tested after a 10-day interval, the aversions to chocolate milk were equivalent in preexposed and nonpreexposed subjects, and were significantly stronger than those found in unpaired control subjects. This effect differs from that found in adults only in that the effects of generalized preexposure and primary preexposure declined equally over the retention interval for the 12day-old rats. Generalized preexposure had no comparable effect in adults (Kraemer \& Ossenkopp, 1985; Kraemer \& Roberts, 1984). This finding extends the generality of the Kraemer-Roberts findings and implies some similarity in the memory processing of the 12-dayold rat and the adult rat, was well as greater generalization for the younger rat.

Because of the unfortunate need to use different consumption tests for 12-day-old rats tested after $20 \mathrm{~h}$ and after 10 days, caution is required when making conclusions about the present effects of retention-interval length. The cannulation procedure necessary for testing 13-dayold rats was deemed inappropriate for 22-day-old rats, since at the older age the operation is believed to be more stressful. The consequences of the operation for the 22day-old rat-including possible interference with taste recognition-and the ready disposition at this age to drink from drinking tubes all contributed to our use of the onebottle consumption test for 12-day-old rats tested at the 10 -day interval. This prevents a retention interval $\times$ treatment analysis of the data, which is typically used to examine differential forgetting, but we believe that the comparison between comparable treatment conditions at each interval is nonetheless informative. This analysis implies, although it does not establish, that the retention interval influenced the expression of preexposure effects in 12day-old rats in a manner similar to that found in adults. Additional research on this issue is certainly desirable, but is unfortunately limited, at least at present, by the above technological constraints.

The same caution must accompany interpretation of simple forgetting by nonpreexposed groups. The betweentreatment comparisons suggest that, over the 10-day interval, the 12-day-old rats retained the conditioned aversion but the 6-day-old rats did not. Yet the drastic increase in gross consumption over the 10-day interval, particularly by the pups conditioned as 6-day-olds, complicates the interpretation of apparent changes in aversion strength over the retention interval. Consumption would be expected to increase not only as a result of forgetting, but also as a result of growth in body size over the retention interval. If consumption, expressed as a percentage of body-weight gain, were not a linear increasing function of body weight, then the comparison of the percentage of body-weight gain at different retention intervals would be an inaccurate measure of the retention of an aversion. A more appropriate basis for the evaluation of general forgetting may be to compare the relative treatment groups separately at each retention interval. This holds for the 6-day-old rats, for the reasons outlined, and is also required for the 12-day-old rats because two different measures of consumption were required for them at the two intervals. The conservative, yet reasonable, conclusion is therefore that the data suggest forgetting in the 6-dayold rats but not the 12-day-old rats. Such a conclusion is consistent with the large array of evidence that has confirmed the occurrence of more rapid forgetting by younger animals (Campbell \& Spear, 1972; Spear, 1978).

It is interesting that the excellent retention found in the 12-day-old rats occurred despite a dramatic change between the consummatory contexts of conditioning and testing. In animals tested after a 10-day interval, the CS was presented through drinking tubes for a 3-min period, whereas during conditioning, this CS was infused orally via a cheek cannula. These animals nevertheless expressed strong aversions. It should also be noted, however, that this contextual change cannot account for all of the present effects. If, after the 10-day interval, the animals were merely manifesting a neophobic response to the chocolate milk in response to the substantial contextual change, then such a reaction should have also appeared in the unpaired control group. However, this did not occur.

In summary, 12-day-old rats given preconditioning expousre to either the CS or a different taste exhibited attenuated conditioning after a $20-\mathrm{h}$ interval, but not after 10 days. Such attenuated conditioning was not evident after either retention interval among 6-day-old rats. This contrasts with the findings of Rudy and Cheatle (1979), in which odor preexposure reduced the strength of a conditioned odor aversion in 7-day-old rats. The similar decrease in the CS - preexposure effect over time among infant (12-day-old) and adult rats-manifested as an increase in retention over a long interval-contrasts with age-related differences in other effects of a retention interval (e.g., Campbell \& Spear, 1972; Smith \& Spear, 1981). Yet this effect confirms a certain robustness to the basic observation indicating that "latent inhibition" is more likely an effect of memory retrieval than of memory storage (Kraemer \& Roberts, 1984).

\section{REFERENCES}

BEST, M. R. (1975). Conditioned and latent inhibition in taste-aversion learning: Clarifying the role of learned safety. Journal of Experimental Psychology: Animal Behavior Processes, 104, 77-113

BEST, M. R., \& GEMBERLNG, G. A. (1977). Role of short-term processes in the conditioned stimulus preexposure effect and the delay of reinforcement gradient in long-delay taste aversion learning. Journal of Experimental Psychology: Animal Behavior Processes, 3, 253-263.

CAMPBel., B. A., \& ALBERTS, J. (1979). Ontogeny of long-term mernory for learned taste aversion. Behavioral \& Neural Biology, 25, 139-156. Campbell, B. A., \& Haroutunian, V. (1979). Perceptual sharpen- 
ing in the developing rat. Journal of Comparative Psychology, 97, 3-11.

Campbell, B. A., \& Spear, N. E. (1972). Ontogeny of memory. Psychological Review, 79, 215-236.

CaZa, P. A., \& Spear, N. E. (1984). Short-term exposure to an odor increases its subsequent preference in preweanling rats: A descriptive profile of the phenomenon. Developmental Psychobiology, 17, 407-422.

DAWLEY, J. M. (1979). Generalization of the CS-preexposure effect transfers to taste aversion learning. Animal Learning \& Behavior, 7 , 23-24.

ELkINS, R. L. (1973). Attenuation of drug-induced bait shyness to a palatable solution as an increasing function of its availability prior to conditioning. Behavioral Biology, 9, 221-226.

Garcia, J., \& Koelling, R. A. (1967). A comparison of aversions induced by X-rays, toxins and drugs in the rat. Radiation Research, 7, 439-450.

Gemberling, G. A., \& Domuan, M. (1982). Selective associations in one-day-old rats: Taste-toxicosis and texture-shock aversion learning. Joumal of Comparative \& Physiological Psychology, 96, 105-113.

Gemberling, G. A., Domuan, M., \& AmSel, A. (1980). Aversion learning in 5-day-old rats: Taste-toxicosis and texture shock associations. Journal of Comparative \& Physiological Psychology, 94, 734-745.

HaLL, W. G., \& RosenblatT, J. (1977). Suckling behavior and intake control in the developing rat pup. Journal of Comparative \& Physiological Psychology, 91, 1232-1247.

HoFrmanN, H. (1985). The effect of odor preexposure on the subsequent associability of that odor in preweanling rats. Unpublished master's thesis, SUNY Binghamton, Binghamton, NY.

Hoffmann, H., Molina, J., Kucharski, D., \& Spear, N. E. (1987). Further examination of ontogenetic limitations on conditioned taste aversion. Developmental Psychobiology, 20, 455-463.

Kalat, J. W., \& Rozin, P. (1973). "Learned safety" as a mechanism in long-delay taste aversion learning in rats. Journal of Comparative \& Physiological Psychology, 83, 198-207.

KEPPEL, G. (1982). Design and analysis (2nd ed.). Englewood Cliffs, NJ: Prentice-Hall.

Kraemer, P. J., \& OssenkopP, K.-P. (1985). The effects of flavor preexposure and test interval on conditioned taste aversions in rats. Bulletin of the Psychonomic Society, 24, 219-221.
Kraemer, P. J., \& Rogerts, W. A. (1984). The influence of flavor preexposure and test interval on conditioned taste aversions in the rat. Learning \& Motivation, 15, 259-278.

Lubow, R. E. (1973). Latent inhibition. Psychological Bulletin, 79, 398-407.

NACHMAN, M. (1970). Learned taste and temperature aversions due to lithium chloride sickness after temporal delays. Joumal of Comparative \& Physiological Psychology, 73, 22-30.

Revusky, S. H., \& BEDARF, E. W. (1967). Association of illness with prior ingestion of novel foods. Science, 155, 161-162.

Rudy, J. W., \& Cheatle, M. D. (1979). Ontogeny of associative learning: Acquisition of odor aversions by neonatal rats. In N. E. Spear \& B. A. Campbell (Eds.), Ontogeny of learning and memory. Hillsdale, NJ: Erlbaum.

Rudy, J. W., VoGT, M. G., \& Hyson, R. L. (1984). A developmental analysis of the rat's leamed reactions to gustatory and auditory stimulation. In R. Kail \& N. Spear (Eds.), Comparative perspectives on the development of memory (pp. 181-208). Hillsdale, NJ: Erlbaum.

Smith, G. J., \& SPEAR, N. E. (1981). Role of proactive interference in infantile forgetting. Animal Learning \& Behavior, 9, 371-380.

SPEAR, N. E. (1978). The processing of memories: Forgetting and retention. Hillsdale, NJ: Erlbaum.

Steinert, P. A., INfuRNa, R. N., \& SPEAR, N. E. (1980). Long-term retention of a conditioned taste aversion in preweanling and adult rats. Animal Learning \& Behavior, 8, 375-381.

TARPY, R. M., \& McINTosh, S. M. (1977). Generalized latent inhibition in taste-aversion learning. Bulletin of the Psychonomic Society, 10, 379-381.

VogEL, J. R., CLODY, D. E. (1972). Habituation and conditioned food aversion. Psychonomic Science, 28, 275-276.

VoGT, M. B., \& RuDY, J. W. (1984a). Ontogenesis of learning: I. Variation in the rat's reflexive and learned responses to gustatory stimulation. Developmental Psychobiology, 17, 11-33.

VoGT, M. B., \& RUDY, J. W. (1984b). The ontogenesis of learning: IV. Dissociation of memory and perceptual processes mediating taste neophobia in the rat. Developmental Psychobiology, 17, 601-611.

(Manuscript received April 27, 1987; revision accepted for publication October $16,1987$. ) 